\title{
Editorial
}

\section{Safety Features of High Temperature Gas Cooled Reactor}

\author{
Chao Fang, ${ }^{1,2,3}$ Robert Morris, ${ }^{4}$ and $\mathrm{Fu} \mathrm{Li}^{1,2,3}$ \\ ${ }^{1}$ Institute of Nuclear and New Energy Technology, Tsinghua University, Beijing 100084, China \\ ${ }^{2}$ Collaborative Innovation Center of Advanced Nuclear Energy Technology, Beijing 100084, China \\ ${ }^{3}$ The Key Laboratory of Advanced Reactor Engineering and Safety, Ministry of Education, Beijing 100084, China \\ ${ }^{4}$ Oak Ridge National Laboratory, Fusion and Materials for Nuclear Systems Division, Oak Ridge, TN 37831, USA \\ Correspondence should be addressed to Chao Fang; fangchao@tsinghua.edu.cn
}

Received 19 October 2017; Accepted 19 October 2017; Published 9 November 2017

Copyright (C) 2017 Chao Fang et al. This is an open access article distributed under the Creative Commons Attribution License, which permits unrestricted use, distribution, and reproduction in any medium, provided the original work is properly cited.

Most of current operating nuclear power plants (NPPs) are light-water reactors (LWR). LWR features, as ceramic fuel, metallic fuel cladding, and core structure, use water as coolant and moderator. The safety of NPPs relies on three basic methodologies: reactivity control, residual heat removal, radioactive retention. For NPP, high safety is achieved by proper design, good quality components, different types of safety systems, and engineering safety features, such as reactor trip, emergency core cooling system, safety injection, decay heat removal system, and containment. In the case of LWR, all accidents, even the design extension condition with core melt (before being named as severe accident), can be controlled and mitigated. For this purpose, reliable cooling of the core and removal of residual decay heat are crucial to preventing core melt, and additional measures must be provided to mitigate the consequences of core melt. In this case, containment plays very important roles. Containment provide many functions, such as radiation shielding, physical protection, radioactive retention, maintaining of coolant inventory (which is crucial to cooling the core and removing the decay heat).

High Temperature Gas Cooled Reactor (HTGR) provides another solution. HTGR uses TRISO coated particle fuel, full ceramic core structure, and helium as coolant. The fuel, core structure, and coolant in HTGR can all withstand high temperature. Therefore HTGR can provide high temperature output for high efficiency electricity generation and wide range of process heat applications, including hydrogen production. Furthermore, modular HTGR can provide inherent safety features.
Although it is based on the same safety function requirements, such as reactivity control, residual heat removal, and radioactive retention, modular HTGR achieved the safety in different way.

The reactivity control is very simple for HTGR. Although reactor trip with control rod drop is equipped, the trip of helium circulator is enough for trip reactor, because the negative temperature feedback provides enough reactivity compensation even for large reactivity insertion accident, taking into account the following fact of residual decay removal mechanism.

For the residual heat removal in modular HTGR, after accident, no forced cooling for the core is required; residual heat is removed from core through the core, reflector, and core barrel and then out of pressure vessel, by means of heat conductivity, radiation, and convection, along the temperature gradient. In this case, availability of coolant is not necessary and external power is not required. Of course, the core will be heated up to some degree to provide the temperature gradient for heat transfer and provide the negative temperature feedback for automatic reactor trip for reactivity control. The maximum core temperature after accident is limited by the accumulation of residual heat, which is proportional to the power density during normal operation and to the temperature limit that the integrity of TRISO fuel is ensured to retain all fission products in all accident conditions, with enough margin. Therefore it is a very simple solution. Neither massive fuel degradation nor core melt will be possible. Therefore it provides a very good foundation for radioactive retention. 
For radioactive retention, it is also very straightforward for modular HTGR. Because the possibility of massive fuel degradation is physically eliminated, almost all the fission products are retained inside the coating of TRISO particle in normal operation and accident condition. The failure rate of TRISO particle is very low for all accident conditions. Then the maximum plausible radioactive release into environment for all accidents is limited to the extent that no off-site emergency action is needed. The goal of catastrophe-free can be achieved by modular HTGR. For modular HTGR, the most important barrier to radioactive retention is TRISO particle, compared to the containment in LWR, although next barriers of primary pressure boundary and containment (usually named as vented lower pressure containment) are also provided in modular HTGR to reduce the radioactive release as low as reasonably achievable.

These safety phenomena and safety features of modular HTGR depend on the high quality of TRISO particle fuel, proper design of core geometry to disperse the residual heat, the selected power density in order to limit the maximum fuel temperature after accident, ceramic core structure and coolant which can withstand very high temperature, and all the measures required to mitigate the consequences of accident and to reduce the radioactive release as low as reasonably achievable. The research on the modular HTGR have many different features, compared to LWR, because of different fuel type (TRISO coated particle), different core structure (graphite), different coolant (helium), different type of components (such as helium circulator), different type of systems (such as fuel handling system for pebble fuel), different operation dynamic behavior, different accident scenario, different applications (such as process heat application and cogeneration), and so forth. This special issue provides some new information and recent progress. Understanding of the safety features of the HTGR has greatly increased especially after the design and construction of Chinese modular HTGR demonstration plant (High Temperature Reactor-Pebble-Bed Module, HTR-PM).

There are a lot of academic achievements related to the safety features of HTGR emerging in the recent years, including, beyond design basis accident (BDBA), multiscale source term analysis, behavior of tritium in the primary and secondary circuit, and minimizing emergency response for the modular HTGR, which is essential for the future improvements in the design, operation, and maintenance of the modular HTGR. The recent progress in this field is addressed in the following:

(1) performance of HTGR fuel

(2) safety and accident analysis of HTGR (including reactor physics analysis, thermal-hydraulics analysis)

(3) source term analysis of HTGR

(4) control of multimodular HTGRs and related human factor analysis

(5) optimizing radiation protection of HTGR

The paper "Oxidation Behavior of Matrix Graphite and Its Effect on Compressive Strength" studies the oxidation behavior of newly developed A3-3 MG in the temperature range from 500 to $950^{\circ} \mathrm{C}$ in air and the effect of oxidation on the compressive strength of oxidized MG specimens. Microstructure images of SEM and porosity measurement indicate that the significant compressive strength loss of $\mathrm{MG}$ oxidized at $550^{\circ} \mathrm{C}$ may be attributed to both the uniform pore formation throughout the bulk and the preferential oxidation of the binder.

The paper "Analysis of Precooling Injection Transient of Steam Generator for High Temperature Gas Cooled Reactor" simulates several postulated precooling injection transients and evaluates their effects, which will provide support for the precooling design. The analysis results show that enough precooling injection must be available to satisfy the precooling requirements, and larger mass flow rate of precooling water injection will accelerate the precooling process.

The paper "Adsorption Behaviors of Cobalt on the Graphite and SiC Surface: A First-Principles Study" presents the adsorption behavior of the activation product cobalt (Co) on graphite and SiC surfaces which have been studied with first-principle calculations, including the adsorption energy, charge density difference, density of states, and adsorption ratios. The results show that the $\mathrm{SiC}$ layer in a fuel element could obstruct the diffusion of Co effectively in normal and accidental operation conditions, but the graphite may become a carrier of Co nuclide radioactivity in the primary circuit of HTR-PM.

The paper "Dynamic Modeling and Control Characteristics of the Two-Modular HTR-PM Nuclear Plant" summarizes the study of the proposed power control system for a two-modular HTR-PM plant and gives the verification results based on numerical simulation. The simulation examines the cases of plant power steps and ramps and shows that the plant control characteristics are satisfactory.

The paper "The Optimization of Radiation Protection in the Design of the High Temperature Reactor-Pebble-Bed Module" proposes a methodology that jointly optimizes the system design and radiation protection of the High Temperature Reactor-Pebble-Bed Module (HTR-PM) within the confines of the "as low as reasonably achievable (ALARA)" principle. It demonstrates that the annual collective dose of HTR$\mathrm{PM}$ is reduced from 0.490 man-Sv/a before optimization to 0.445 man-Sv/a after optimization, which complies with the requirements of the Chinese regulatory guide and proves the effectiveness of the proposed routine and framework.

The paper "A New Method to Measure Crack Extension in Nuclear Graphite Based on Digital Image Correlation" introduces a new method based on digital image correlation (DIC) for measuring crack extension in brittle materials. Cross-correlation of the displacements measured by DIC with a step function is employed to identify the advancing crack tip in a graphite beam specimen under three-point bending. The load-crack extension curve, which is required for analyzing the R-curve and tension softening behavior, is obtained for this material. Furthermore, a sensitivity analysis of the threshold value employed for the cross-correlation parameter in the crack identification process is conducted.

The paper "Research on the Computed Tomography Pebble Flow Detecting System for HTR-PM" constructs 
a computed tomography pebble flow detecting (CT-PFD) system to study pebble dynamics in which a three-dimensional model is simulated, scaled to the ratio of 1:5 based on the core of HTR-PM. A multislice helical CT is utilized to acquire the reconstructed cross-sectional images of simulated pebbles, among which special tracer pebbles are used to indicate pebble flow. The proposed pebble-detecting and tracking technique described in this paper will be implemented in the near future.

Overall, the main purpose of this special issue is to provide a platform for sharing the latest and significant research achievements on the safety features of the HTGR. We believe that this special issue will supply interesting information on the safety features of HTGR.

\section{Acknowledgments}

We would like to express gratitude to all those who helped us during organizing this special issue and express heartfelt gratitude to Mr. Liguo Zhang, who supplied abundant materials about HTGRs for reference in the process of writing this editorial.

Chao Fang

Robert Morris

$\mathrm{Fu} \mathrm{Li}$ 


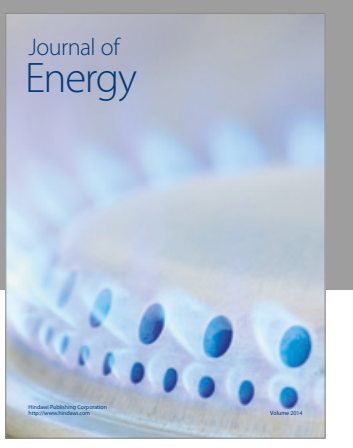

Journal of

Industrial Engineering
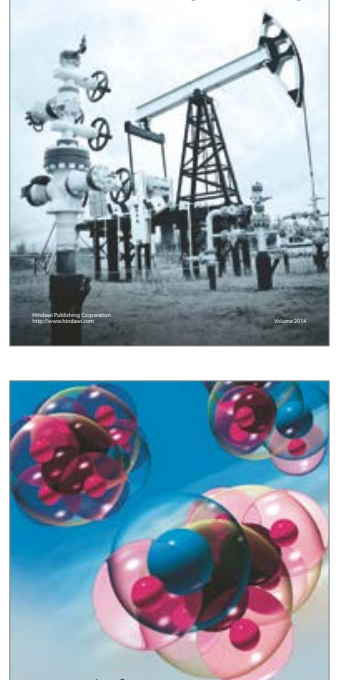

Fuels
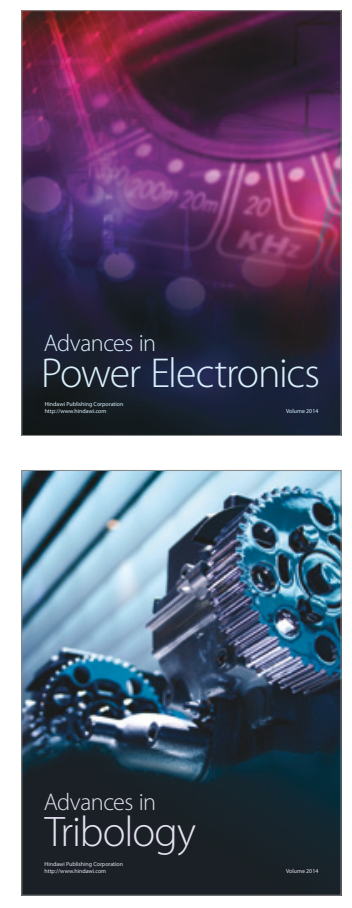
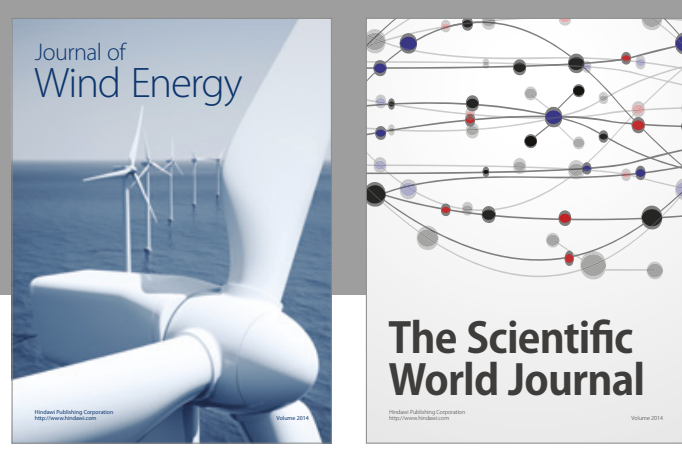

The Scientific World Journal
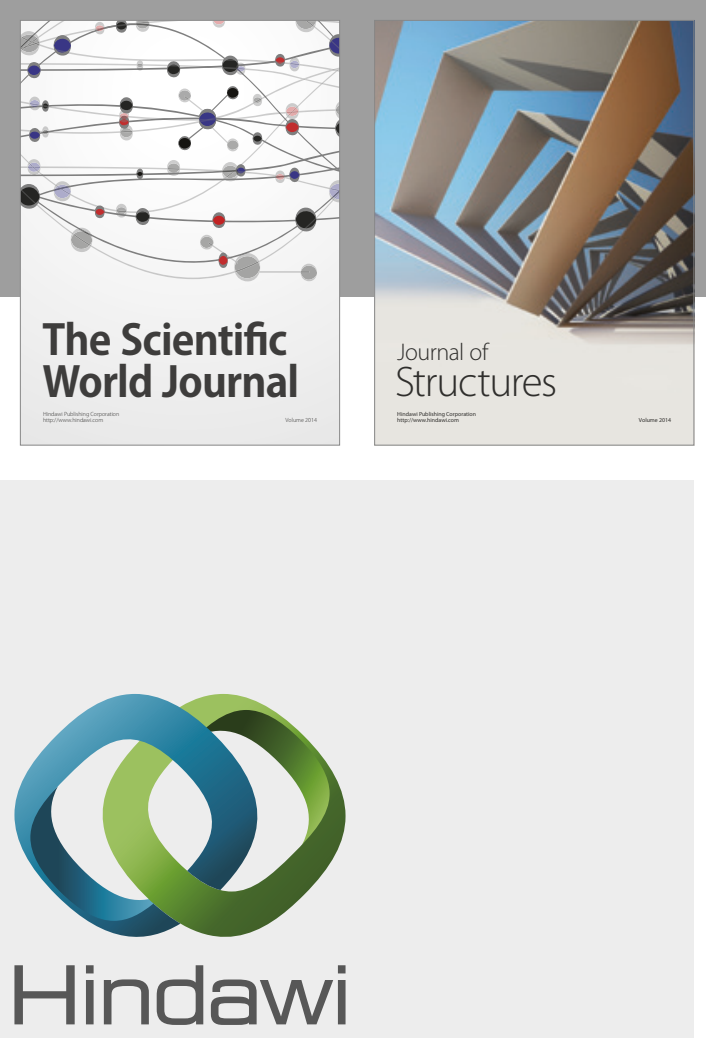

Submit your manuscripts at

https://www.hindawi.com
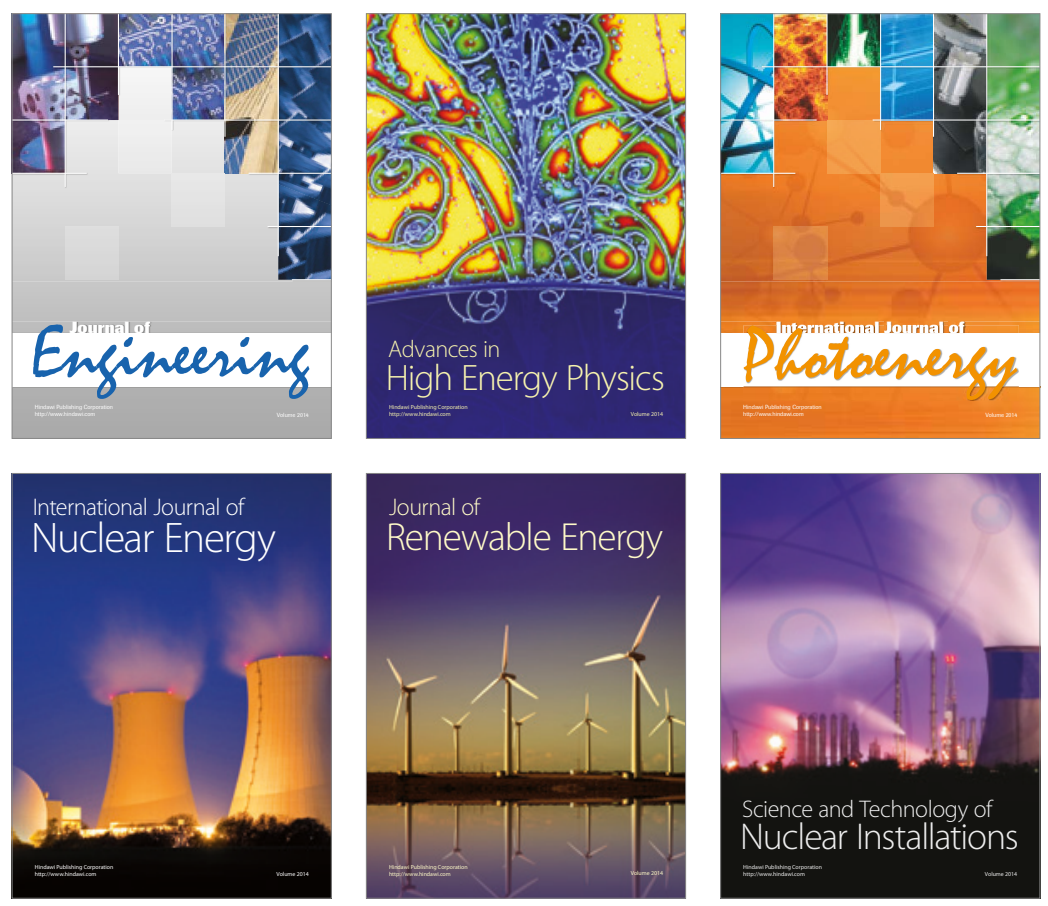

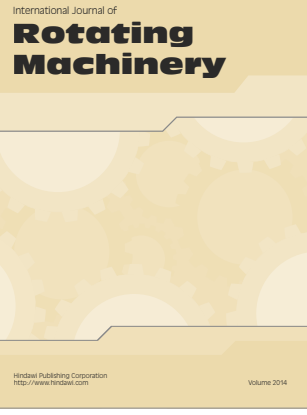

Journal of

Petroleum Engineering

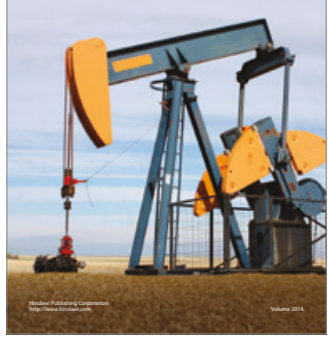

Journal of
Solar Energy
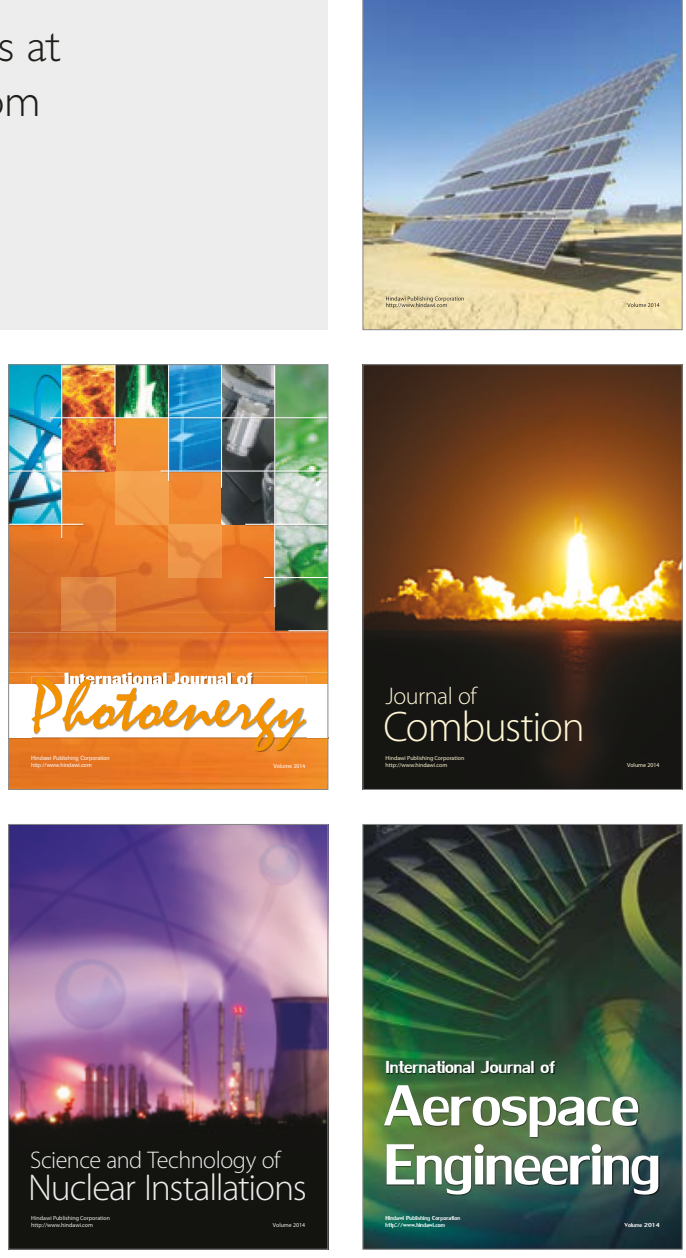